\title{
Cord blood leptin and gains in body weight and fat mass during infancy
}

\section{Carol ní Chaoimh ${ }^{1,2}$, Deirdre M Murray2,3, Louise C Kenny ${ }^{2,4}$, Alan D Irvine ${ }^{5,6}$, Jonathan O'B Hourihane ${ }^{2,3}$ and Mairead Kiely ${ }^{1,2}$}

${ }^{1}$ Cork Centre for Vitamin D and Nutrition Research, School of Food and Nutritional Sciences, ${ }^{2}$ The Irish Centre for Fetal and Neonatal Translational Research (INFANT), ${ }^{3}$ Department of Paediatrics and Child Health, ${ }^{4}$ Department of Obstetrics and Gynaecology, University College Cork, Cork, Ireland, ${ }^{5}$ Department of Clinical Medicine, Trinity College Dublin, Dublin, Ireland, and ${ }^{6}$ Our Lady's Children's Hospital Crumlin, Dublin, Ireland
Correspondence should be addressed to M Kiely

Email m.kiely@ucc.ie

\begin{abstract}
Objectives: Low early-life leptin concentrations may promote faster weight gain in infancy. We aimed to examine the associations between cord blood leptin concentrations and changes in weight and body composition during infancy. Design and methods: Serum leptin was measured at 15 weeks gestation, in umbilical cord blood collected at delivery and at 2 years in 334 children from the Cork Baseline Birth Cohort Study. Body composition was measured at 2 days and 2 months using air displacement plethysmography. Conditional change in weight standard deviation scores over a number of age intervals in the first 2 years and conditional change in fat mass index (FMI) and fat-free mass index (FFMI) $\left(\mathrm{kg} /(\right.$ length $\left.) \mathrm{m}^{2}\right)$ between birth and 2 months were calculated and associations with cord blood leptin were examined using linear regression.

Results: At birth, cord blood leptin was positively correlated with FMI $(r=0.48, P<0.001)$ and showed a weaker correlation with FFMI $(r=0.12, P=0.05)$. After adjustment for confounders, higher cord blood leptin $(\mathrm{per} \mathrm{ng} / \mathrm{mL})$ was associated with slower conditional weight gain between birth and 2 months $(\beta(95 \% \mathrm{Cl}):-0.024(-0.035,-0.013)$, $P<0.001)$ but not over subsequent age intervals. Cord blood leptin was also inversely associated with conditional change in FMI $(-0.021(-0.034,-0.007, P=0.003)$ but not FFMI between birth and 2 months.

Conclusions: These are the first data to show that associations between higher cord blood leptin and slower weight gain during infancy are driven by lower increases in adiposity, at least in early infancy.
\end{abstract}

\section{Introduction}

Rapid weight gain in infancy is associated with an increased risk of obesity in childhood and adulthood $(1,2)$ and may affect subsequent metabolic health $(3,4)$. Currently, there are few data on determinants of rapid weight gain in infancy, but both prenatal and early-life factors have been implicated $(5,6)$. Leptin, a product of the $o b$ gene, is a $16 \mathrm{kDa}$ hormone secreted primarily by adipocytes, but is also produced in other sites, including fetal and placental tissues $(7,8)$. In adults, the primary role of leptin is in energy homeostasis through the regulation of appetite and energy expenditure via a number of neuronal signals $(9,10)$. There is now emerging evidence to suggest that
() 2016 European Society of Endocrinology Printed in Great Britain low fetal leptin concentrations mediate faster weight gain during infancy and play a role in the development of obesity $(11,12,13)$.

Evidence from animal models suggests that lower umbilical cord blood leptin may be a marker of adverse intrauterine conditions including placental insufficiency and fetal growth restriction, resulting in lower fat mass at birth, permanent changes in appetite regulation and faster postnatal growth $(10,14,15)$. In rodents, leptin plays a role in the programming of hypothalamic appetite regulation in the early postnatal period, and it has been demonstrated that disruption in the action of leptin by leptin antagonists

Published by Bioscientifica Ltd. 
during this critical period of hypothalamic development leads to long-term consequences including hyperphagia, obesity and leptin resistance in adulthood $(15,16,17)$. In humans, development of the hypothalamic feeding circuits occurs primarily in utero during the final trimester (18) and thus leptin during the pre- and perinatal periods may be important. Umbilical cord blood leptin has been consistently shown to be positively associated with birth weight and has been widely accepted as a marker of neonatal adiposity $(13,19,20)$. Cord blood leptin concentrations have also been shown to be inversely associated with weight gain in infancy $(11,12,21)$ and with body mass index (BMI) in early childhood (20). However, weight and BMI are limited as proxies of adiposity as they correlate with both fat and lean mass. To date, no study has examined cord leptin in relation to changes in direct measures of body composition in infancy. The aim of this study was to examine the associations between umbilical cord blood leptin concentrations collected at delivery and changes in both weight and adiposity in early infancy.

\section{Subjects and methods}

Study subjects were participants of the Cork BASELINE (Babies after SCOPE: Evaluating the Longitudinal Impact using Neurological and Nutritional Endpoints) Birth Cohort Study (22). This mother-infant prospective birth cohort study based in Cork, Ireland, was initiated in 2008 as a follow-up to the SCOPE (Screening for Pregnancy Endpoints) Ireland study, as part of a major multicenter prospective pregnancy study involving primiparous low-risk women. The SCOPE study is registered with the Australian New Zealand Clinical Trials Registry (http://www.anzctr.or.au), ID: ACTRN12607000551493. A detailed description of the SCOPE methodology has been provided elsewhere (23).

A total of 1768 women were recruited to SCOPE Ireland from Cork University Maternity Hospital (CUMH). During the 20 week gestation visit, 1537 SCOPE participants provided informed consent for their infants to participate in the BASELINE study. During a second stream of recruitment, a further 600 infants were recruited after delivery from the postnatal wards of CUMH, with the last infant recruited in 2011. Pediatric follow-up with in-person assessments were conducted at birth 2, 6 and 12 months and at 2 years. Data on the child's early-life environment, diet, health and development were recorded at each assessment. A detailed description of the cohort and pediatric assessments has been provided by $\mathrm{O}^{\prime}$ Donovan et al. (22). Ethical approval for the Cork BASELINE Birth
Cohort Study was granted by the Clinical Research Ethics Committee of the Cork Teaching Hospitals, ref ECM 5 (9) 01/07/2008, and the study is registered with the United States National Institutes of Health Clinical Trials Registry (http://www.clinicaltrials.gov), ID: NCT01498965.

Of the 2137 infants recruited to the Cork BASELINE Birth Cohort Study, 1954 infants continued with the study and had follow-up information collected after the initial assessment at birth. Umbilical cord blood was only collected from those recruited from the SCOPE study. At the time of the current analysis, cord blood was available for 1050 infants. A total of 1537 children attended the 2 year assessment, of which 742 (48\%) had a serum sample collected at 2 years. Cord blood and 2year leptin concentrations were only measured in those with both a cord and 2 year blood sample available $(n=346)$. In the current analysis, preterm infants $(n=12)$ were excluded due to potential differences in their early growth patterns, leaving a cohort of 334 infants.

\section{Anthropometry}

Naked weight was measured using digital scales (seca 384, seca, Birmingham, UK) at birth and at 2 months correct to the nearest $0.01 \mathrm{~kg}$ and at 6 and 12 months and at 2 years correct to the nearest $0.1 \mathrm{~kg}$. Supine length correct to the nearest $0.1 \mathrm{~cm}$ was measured at birth, 2, 6 and 12 months (seca 210). At 2 years, standing height was measured using a wall mounted stadiometer (seca 206). Age- and sex-specific weight standard deviation scores (SDS) were generated using LMS growth software (24) and the UK-World Health Organization (WHO) 0-4year growth reference data (25). BMI $\left(\mathrm{kg} / \mathrm{m}^{2}\right)$ and BMI SDS at 2 years were calculated. Overweight and obesity at 2 years were defined using the UK-WHO age- and sex-specific BMI charts (25), where overweight was defined as a BMI >91st percentile and obesity as a BMI>98th percentile (26). Small-for-gestational age (SGA) and large-for-gestational age (LGA) infants were defined as a birth weight $<10$ th and $>90$ th percentile respectively using customised percentiles adjusted for maternal height, booking weight and ethnicity and for infant gestational age and sex (27). Fat mass (FM) and fat-free mass (FFM) (kg) were measured within 4 days of birth (mean (s.D.): 1.9 (1.0) days) and at 2 months (2.1 (0.3) months) in 221 infants by air displacement plethysmography using the PEA POD Infant Body Composition Tracking System (COSMED USA, Inc, Concord, CA, USA). To adjust body composition variables for body size, fat mass index (FMI) and fat-free mass index (FFMI) were calculated by dividing FM and FFM by length in metres squared $\left(\mathrm{kg} / \mathrm{m}^{2}\right)$ respectively. 


\section{Sample collection and analysis}

Umbilical cord venous blood samples collected at delivery and peripheral venous blood samples collected at 2 years were immediately stored at $5^{\circ} \mathrm{C}$ and then processed to serum within $3 \mathrm{~h}$ for storage in small aliquots $(200 \mu \mathrm{L})$ at $-80^{\circ} \mathrm{C}$ until analysis. Leptin concentrations were measured in duplicate at the Cork Centre for Vitamin D and Nutrition Research laboratory by a Quantikine enzyme-linked immunosorbant assay (ELISA) (DLP00, R\&D Systems) using an automated processing system (DS2, DYNEX Technologies Ltd, Worthing, UK). The assay sensitivity was $7.8 \mathrm{pg} / \mathrm{mL}$. The inter- and intra-assay coefficients of variation (CV) were 8.7 and $4.0 \%$, respectively. Maternal leptin concentrations at 14-16 weeks gestation were measured previously by Luminex Sandwich Assay (Alere, San Diego, CA, USA), as described by Kenny et al. (23).

\section{Outcome variables}

As growth during a specific period is likely predicted by earlier growth, conditional models of weight gain were constructed using linear regression analysis. Conditional growth represents the variation in infant growth not explained by prior growth, providing uncorrelated measures (28). For example: conditional weight gain between birth and 2 months was calculated by saving the standardised residuals from the linear regression of weight SDS at 2 months on weight SDS at birth. Conditional weight gain between 2 and 6 months is given as the standardised residuals from the regression of weight SDS at 6 months on weight SDS at 2 months and at birth. This process was continued when calculating conditional weight gain between 6 and 12 months and between 12 and 24 months. Conditional change in FMI and FFMI $\left(\mathrm{kg} / \mathrm{m}^{2}\right)$ from birth to 2 months was also calculated by saving the standardised residuals from the regression of the measurement at 2 months on the measurement at birth.

\section{Statistical analysis}

Data were analysed using the statistical software package IBM SPSS for Windows version 21.0 (IBM released 2012). Most variables were nonparametric and are presented as medians or percentages. Characteristics were compared between groups using $\chi^{2}$ or Mann-Whitney $U$ tests, where appropriate. Spearman's correlation coefficients were calculated to examine relationships between cord blood leptin and measurements at birth and 2 years.

Unadjusted associations between umbilical cord blood leptin and conditional change in weight and body composition during infancy were examined using linear regression. Multivariate models were adjusted for maternal and infant variables that were considered $a$ priori as confounders in the main associations. These included maternal age at delivery, overweight/obesity at 15 weeks gestation $\left(\geq 25 \mathrm{~kg} / \mathrm{m}^{2}\right)$, smoking during pregnancy, tertiary level education, family income and infant sex, gestational age, breastfeeding status and age at introduction to solids (weeks). In order to examine the association between relatively lower cord blood leptin concentrations and BMI SDS at 2 years, unadjusted trend $P$ values across quartiles of cord blood leptin were calculated using linear regression, with the lowest quartile as a reference. Multivariate models were first adjusted for birth weight and then further adjusted for a priori maternal and infant confounders. All statistical tests were two-tailed and a value of $P<0.05$ was considered statistically significant.

\section{Results}

Maternal and subject characteristics of those included in the current analysis, as well as a comparison with those not included in the analysis, are presented in Table 1. Compared with those not included in the analysis, the median maternal BMI in this subgroup was slightly higher (median (interquartile range, IQR): 24.5 (22.4, 27.2) vs $\left.23.8(21.9,26.8) \mathrm{kg} / \mathrm{m}^{2}, P=0.033\right)$, and a higher proportion of infants were predominantly breastfed at 2 months ( 33.4 vs $25.8 \%, P=0.006$ ). Females had higher leptin concentrations at birth than males (median (IQR): $12.8(8.5,19.6)$ vs $8.3(5.3,13.1) \mathrm{ng} / \mathrm{mL})$ and at 2 years $(2.4$ $(1.7,3.1)$ vs $1.6(1.2,2.3) \mathrm{ng} / \mathrm{mL}), P<0.001$ for both. SGA infants had significantly lower cord leptin concentrations (median (IQR): $5.6(3.4,8.2) \mathrm{ng} / \mathrm{mL}$ ) than average-forgestational age (AGA) $(10.3(6.3,17.1) \mathrm{ng} / \mathrm{mL})$ and LGA infants $(14.5(10.5,33.1) \mathrm{ng} / \mathrm{mL}), P<0.001$. At 2 years, there was no significant difference in leptin concentrations between the groups, with median (IQR) concentrations of $2.0(1.2,2.6), 2.0(1.4,2.7)$ and $2.0(1.3,2.6) \mathrm{ng} / \mathrm{mL}$ in SGA, AGA and LGA infants respectively, $P=0.68$.

The median (IQR) maternal leptin concentration at $14-16$ weeks was higher in mothers whose BMI was $\geq 30 \mathrm{~kg} / \mathrm{m}^{2}(n=37)$ at $14-16$ weeks gestation (11.8 (6.7, $17.1) \mathrm{ng} / \mathrm{mL}$ ) compared with those with a BMI $<25 \mathrm{~kg} / \mathrm{m}^{2}$ $(n=179)(6.4(5.5,13.6) \mathrm{ng} / \mathrm{mL}), P=0.007$. Cord leptin concentrations were also higher in infants of obese mothers $(12.0(7.5,23.0) \mathrm{ng} / \mathrm{mL})$ compared with those with a $\mathrm{BMI}<25 \mathrm{~kg} / \mathrm{m}^{2}(9.9(5.8,15.6) \mathrm{ng} / \mathrm{mL}), P=0.025$. Maternal and cord blood leptin concentrations were weakly correlated $(r=0.163, P=0.003)$. There was no 
Table 1 Maternal and infant characteristics at birth and 2 years $(n=334)$. Data are presented as $\%(n)$ or median (IQR).

\begin{tabular}{l}
\hline \\
Maternal characteristics \\
Caucasian \\
Third-level education \\
Smoked during pregnancy \\
Age at delivery (<25years) \\
BMI at 14-16 weeks gestation $\left(\mathrm{kg} / \mathrm{m}^{2}\right)$ \\
Leptin at 14-16 weeks gestation $(\mathrm{ng} / \mathrm{mL})$ \\
Infant characteristics \\
Sex (male) \\
Gestational age (weeks) \\
Birth weight (kg) \\
Birth weight SDS \\
SGA (yes) \\
LGA (yes) \\
Predominantly breastfed $2 \mathrm{months}$ \\
Predominantly breastfed $6 \mathrm{months}$ \\
Cord blood leptin (ng/mL) \\
Body composition \\
Fat mass index at birth $\left(\mathrm{kg} / \mathrm{m}^{2}\right)$ \\
Fat free mass index at birth $\left(\mathrm{kg} / \mathrm{m}^{2}\right)$ \\
Fat mass index at $2 \mathrm{months}\left(\mathrm{kg} / \mathrm{m}^{2}\right)$ \\
Fat free mass index at $2 \mathrm{months}\left(\mathrm{kg} / \mathrm{m}^{2}\right)$ \\
Change in FMI from 0 to $2 \mathrm{months}\left(\mathrm{kg} / \mathrm{m}^{2}\right)$ \\
Change in FFMI from 0 to $2 \mathrm{months}\left(\mathrm{kg} / \mathrm{m}^{2}\right)$ \\
Change in weight SDS \\
$0-2$ months \\
$0-6$ months \\
$0-12$ months \\
Child characteristics at $2 \mathrm{years}$ \\
Age at assessment (years) \\
BMI SDS \\
2 year leptin (ng/mL) \\
Overweight \\
Obese \\
\hline
\end{tabular}

\begin{tabular}{c}
\hline Not included in the analysis $(n=1620)$ \\
$98.0(1576)$ \\
$84.3(1354)$ \\
$13.2(208)$ \\
$9.0(146)$ \\
$23.8(21.9,26.8)$ \\
$8.3(5.5,14.9)$ \\
$50.7(822)$ \\
$40.1(39.1,41.0)$ \\
$3.50(3.18,3.81)$ \\
$0.20(-0.44,0.84)$ \\
$10.8(119)$ \\
$10.2(112)$ \\
$25.8(405)$ \\
$11.6(172)$ \\
- \\
$1.40(1.01,1.86)$ \\
$11.57(11.03,12.20)$ \\
$3.4(2.9,4.0)$ \\
$12.4(11.8,13.0)$ \\
$2.07(1.44,2.61)$ \\
$0.88(0.28,1.47)$ \\
$-0.21(-0.70,0.26)$ \\
$0.10(-0.48,0.70)$ \\
$0.35(-0.32,1.02)$ \\
$2.1(2.1,2.2)$ \\
$0.69(0.12,1.24)$ \\
- \\
$14.6(162)$ \\
$6.3(70)$ \\
\\
\\
\\
\\
\\
\\
\end{tabular}

\begin{tabular}{c}
\hline Included in the analysis $(n=334)$ \\
\hline $99.1(331)$ \\
$85.0(284)$ \\
$13.3(44)$ \\
$6.6(22)$ \\
$24.6(22.4,27.2)$ \\
$7.7(5.5,14.8)$
\end{tabular}

P-value

0.255

0.786

1.000

0.183

0.033

0.577

52.4 (175)

$40.2(39.4,41.4)$

0.624

0.004

$3.51(3.29,3.76)$

0.111

$\begin{array}{ll}0.19(-0.30,0.70) & 0.766 \\ 8.7(29) & 0.310\end{array}$

$12.3(41)$

0.322

0.006

$33.4(111)$

$15.5(51)$

$10.4(6.3,17.2)$

0.063

$-$

$1.4(1.08,1.9) \quad 0.298$

$11.61(11.08,12.20) \quad 0.739$

$3.5(2.9,4.1) \quad 0.809$

$12.5(11.9,13.0) \quad 0.539$

$1.99(1.31,2.66) \quad 0.505$

$0.77(0.30,1.42) \quad 0.635$

$-0.23(-0.73,0.32) \quad 0.632$

$0.16(-0.62,0.82) \quad 0.761$

$0.41(-0.33,1.19) \quad 0.518$

$2.1(2.1,2.2) \quad 0.002$

$\begin{array}{lc}0.68(0.06,1.30) & 0.755 \\ 2.0(1.4,2.7) & -\end{array}$

$2.0(1.4,2.7)$

$15.2(50)$

0.753

$6.8(22)$

0.689

BMI, body mass index; IQR, inter-quartile range; LGA, large-for-gestational age; SDS, standard deviation score; SGA, small-for-gestational age.

correlation between maternal leptin concentrations and infant birth weight SDS $(r=0.073, P=0.181)$, FMI at birth $(r=0.067, P=0.265)$ or FFMI at birth $(r=0.043, P=0.476)$.

Table 2 presents Spearman's correlation coefficients between cord leptin and various measurements at birth and 2 years. Cord leptin was positively correlated with weight and adiposity and showed weaker correlations with lean mass (FFM and FFMI) at birth. After adjustment for FM and FMI at birth respectively, cord leptin concentrations were no longer correlated with FFM and FFMI $(r=0.07$ and $r=0.05$, respectively, $P>0.05$ for both).

Cord blood leptin $(\mathrm{ng} / \mathrm{mL})$ was inversely associated with conditional weight gain between birth and 2 months (Table 3). There were no associations between cord blood leptin concentrations and conditional weight gain over subsequent age intervals in the first 2 years. Cord blood leptin was also inversely associated with conditional
Table 2 Correlations between cord blood leptin and measurements at birth and 2 years*.

\begin{tabular}{|c|c|c|}
\hline & $\boldsymbol{r}$ & $P$-value \\
\hline \multicolumn{3}{|c|}{ Weight and body composition at birth } \\
\hline Birth weight SDS & 0.47 & $<0.001$ \\
\hline Birth length SDS & 0.29 & $<0.001$ \\
\hline $\mathrm{FM}(\mathrm{kg})$ & 0.49 & $<0.001$ \\
\hline FMI $\left(\mathrm{kg} / \mathrm{m}^{2}\right)$ & 0.48 & $<0.001$ \\
\hline FFM $(\mathrm{kg})$ & 0.23 & $<0.001$ \\
\hline FFMI $\left(\mathrm{kg} / \mathrm{m}^{2}\right)$ & 0.12 & 0.05 \\
\hline \multicolumn{3}{|c|}{ Anthropometry and leptin at 2 years } \\
\hline Weight SDS & 0.07 & 0.18 \\
\hline Length SDS & 0.06 & 0.30 \\
\hline BMI SDS & 0.02 & 0.79 \\
\hline Leptin & 0.07 & 0.20 \\
\hline
\end{tabular}

BMI, body mass index; FFM, fat free mass; FFMI, fat free mass index; FM fat mass; FMI, fat mass index; SDS, standard deviation score.

*Spearman correlation coefficients. 
Table 3 Association between cord blood leptin (per $\mathrm{ng} / \mathrm{mL}$ ) and conditional weight gain in the first 2 year of life and conditional change in body composition in the first 2 months.

\begin{tabular}{l}
\hline Variable \\
\hline Conditional weight gain \\
$0-2$ months* \\
$2-6$ months \\
\\
$6-12$ months \\
$12-24$ months \\
Conditional change in body composition \\
FMI 0-2 months* \\
FFMI 0-2 months*
\end{tabular}

Unadjusted estimate $(95 \% \mathrm{Cl})$
$-0.023(-0.033,-0.012)$
$0.002(-0.008,0.013)$
$0.005(-0.006,0.017)$
$0.001(-0.011,0.012)$
$-0.020(-0.033,-0.007)$
$-0.012(-0.024,0.001)$

\begin{tabular}{r}
\hline $\boldsymbol{P}$-value \\
\hline$<0.001$ \\
0.673 \\
0.391 \\
0.880 \\
\\
0.003 \\
0.081
\end{tabular}

Adjusted estimate $(95 \% \mathrm{Cl})$
$-0.024(-0.035,-0.013)$
$0.002(-0.009 .0 .013)$
$0.005(-0.007,0.018)$
$0.000(-0.013,0.012)$
$-0.021(-0.034,-0.007)$
$-0.004(-0.017,0.008)$

P-value

$<0.001$

0.738

0.385

0.956

0.003

0.484

95\% Cl, 95\% confidence interval; FMI, fat mass index; FFMI, fat free mass index.

* Model adjusted for maternal age, maternal BMI $>25 \mathrm{~kg} / \mathrm{m}^{2}$ at 15 weeks gestation, maternal tertiary level education, family income, maternal smoking during pregnancy and infant sex, gestational age, breastfeeding status at 2 months; ${ }^{5}$ Model adjusted for maternal age, maternal BMl $>25 \mathrm{~kg} / \mathrm{m}^{2}$ at 15 weeks gestation, maternal tertiary level education, family income, maternal smoking during pregnancy and infant sex, gestational age, breastfeeding status at 6 months and age (weeks) at introduction to solids.

change in FMI between birth and 2 months but was not associated with conditional change in FFMI.

Cord blood leptin concentrations were not correlated with weight, length or BMI SDS at 2 years or with 2-year leptin concentrations (Table 2). In the linear regression analysis, compared with the lowest quartile of cord blood leptin, there was no significant association between higher cord leptin concentrations and BMI SDS at 2 years in the unadjusted model or after adjustment for confounders including birth weight SDS (Table 4). Leptin concentrations at 2 years were correlated with BMI SDS at 2 years $(r=0.455)$ and the median (IQR) 2-year leptin concentration was higher in those classified as overweight/ obese compared with nonoverweight/obese 2 year olds $(2.6(2.0,3.7)$ vs $1.8(1.2,2.6) \mathrm{ng} / \mathrm{mL}, P<0.001)$.

\section{Discussion}

We have shown that cord blood leptin is positively associated with fat mass at birth and that higher cord leptin concentrations are associated with slower conditional weight gain in early infancy, driven by lower changes in fat mass. To our knowledge, this is the first study to relate umbilical cord blood leptin concentrations to changes in direct measures of body composition in infancy.

Consistent with findings from three other prospective studies $(11,12,21)$, we found that cord blood leptin was inversely associated with weight gain in early infancy. These data suggest that unlike in adults and older children, where high leptin concentrations are indicative of leptin resistance (29), young infants are sensitive to the appetiteand weight-regulating effects of leptin. However, for the first time, we have also shown that cord blood leptin was inversely associated with changes in fat mass index (FMI), but not with changes in fat-free mass index (FFMI) in the early postnatal period. These data suggest that the influence of neonatal leptin concentrations on early postnatal weight gain is through the moderation of fat accretion.

Research into animal models has provided evidence for a number of potential mechanisms whereby lower cord leptin concentrations lead specifically to increases in fat mass. Leptin receptor expression in adipose tissue has been demonstrated in a number of species, including humans, supporting a role for leptin in adipocyte metabolism (31). Studies in rat models have shown that leptin influences adipocyte insulin sensitivity resulting in reduced glucose

Table 4 Associations between quartiles of umbilical cord blood leptin and BMI SDS at 2 years.

\begin{tabular}{|c|c|c|c|c|c|}
\hline & \multicolumn{5}{|c|}{ Difference in mean BMI SDS at 2 years vs Q1 } \\
\hline & Q1 & Q2 & Q3 & Q4 & $P$-trend \\
\hline Cord leptin, median (range) ng/mL & $4.3(0.6-<6.0)$ & $8.1(6.0-<10.1)$ & $12.7(10.2-<17.1)$ & $24.4(17.1-73.9)$ & \\
\hline Model 1, unadjusted & 0.000 & $-0.07(-0.36,0.21)$ & $0.07(-0.21,0.35)$ & $0.02(-0.27,0.30)$ & 0.659 \\
\hline Model 2, adjusted for birth weight SDS & 0.000 & $-0.19(-0.46,0.09)$ & $-0.14(-0.43,0.15)$ & $-0.27(-0.57,0.04)$ & 0.137 \\
\hline Model 3, final model* & 0.000 & $-0.22(-0.51,0.06)$ & $-0.14(-0.44,0.16)$ & $-0.27(-0.59,0.05)$ & 0.258 \\
\hline
\end{tabular}

SDS, standard deviation score; $95 \% \mathrm{Cl}, 95 \%$ confidence interval.

* Model adjusted for maternal age, maternal BMI> $25 \mathrm{~kg} / \mathrm{m}^{2}$ at 15 weeks gestation, maternal tertiary level education, family income, maternal smoking during pregnancy and infant sex, birth weight SDS, gestational age, breastfeeding status at 6 months and age (weeks) at introduction to solids. 
uptake by adipocytes and decreased lipogenesis (30). We found that cord blood leptin concentrations were positively associated with weight and FMI at birth and were significantly lower in SGA infants, indicating that low cord blood leptin may reflect intrauterine growth restriction (IUGR). Attig et al. (31) have shown that IUGR piglets display greater increases in adiposity after weaning upon free access to food than normal-weight controls (29). The same authors have reported that the expression of leptin receptor $(\mathrm{ObRb})$ among the hypothalamic nuclei differed between normal birth weight and IUGR piglets, possibly reflecting an immature stage of neuronal development. This altered pattern of expression may disrupt neuronal pathways through which leptin regulates feeding behaviour and adipocyte metabolism $(31,32)$. IUGR piglets were also shown to have altered adipocyte morphology and a high density of small white adipocytes at 14 days, indicating an increased capacity for lipid storage. Postnatal leptin administration to IUGR piglets starting at 2 days resulted in an adipocyte morphology similar to that of normal-weight controls, indicating that leptin treatment may correct a propensity toward excess fat deposition (31).

Two studies with repeat anthropometric measurements during infancy reported that inverse associations between cord blood leptin and weight gain persisted from birth into early childhood $(11,21)$. However, these studies did not report on associations between cord leptin and weight gain over intermediate age intervals during infancy, limiting the ability to identify independent critical periods. In the current study, we found no association between cord blood leptin and conditional weight gain between 2 and 6 months, 6 and 12 months or 12 months and 2 years, suggesting that cord blood leptin's influence on postnatal weight gain trajectory operates in the early postnatal period.

We found no significant association with BMI SDS at 2 years across quartiles of cord blood leptin. However, after adjustment for potential confounders including birth weight SDS, consistent inverse, but nonsignificant associations across quartiles of leptin, were observed. Two previous studies reported inverse associations between cord blood leptin and BMI in early childhood and have suggested that early-life leptin concentrations may play a role in the development of obesity $(20,21)$. Our ability to detect an inverse association may have been limited by our relatively small sample size.

Data on leptin concentrations throughout infancy and into childhood is limited. Unlike Mantzoros et al. (20), who reported that cord leptin was positively associated with leptin at 3 years, we found no association between cord and 2-year leptin concentrations. Our finding indicates that leptin in early childhood may reflect current nutritional status rather than intrauterine exposures. This is supported by our observation that despite significantly lower cord leptin concentrations in SGA infants compared with AGA and LGA infants, there were no significant differences in 2-year leptin concentrations between the groups.

Reports on the association between maternal leptin concentrations in pregnancy and anthropometric measures at birth are conflicting $(21,33,34)$, and differential effects of maternal leptin across pregnancy and between overweight/ obese and normal weight mothers on fetal growth have been described $(35,36)$. We found a weak correlation between maternal and cord blood leptin concentrations but no correlation between maternal leptin in early pregnancy and weight and body composition measurements at birth. However, our ability to assess these relationships may have been limited due to the use of different assays to measure maternal and cord leptin concentrations and the lack of data on maternal concentrations beyond the first trimester. In agreement with previous reports, maternal obesity was associated with higher maternal $(35,37)$ and cord $(34,36$, $38,39)$ leptin concentrations. Maternal contributions to fetal leptin concentrations are believed to be minimal, with fetal leptin concentrations mainly derived from synthesis in fetal adipose tissue (40). Studies have shown that increased circulating maternal leptin concentrations and a high maternal BMI are associated with greater mobilisation of nutrients in utero and higher fetal plasma glucose and insulin concentrations, leading to increased fetal adiposity and leptin synthesis (41).

In the current study, those who were overweight/ obese at 2 years had higher 2-year leptin concentrations than nonoverweight/obese children. Data from a number of studies suggest that a reversal in the association between leptin and growth occurs early in childhood $(42,43,44)$. Among participants of Project Viva in the US, cord blood leptin was inversely associated with BMI SDS at 3 years, while higher 3-year leptin concentrations were associated with greater weight gain between 3 and 7 years and a higher BMI, waist circumference and fat mass at 7 years (44). Thus, the higher leptin concentrations observed in overweight/obese children at 2 years in the current study could potentially be a reflection of leptin resistance, which may lead to greater weight gain and adiposity in later childhood.

To our knowledge, this is the first study to relate cord leptin to changes in direct measures of body composition in early infancy. Other strengths of this study include its prospective design, the availability of data on a number of pre- and perinatal factors, including maternal leptin 
concentrations in early pregnancy, and the multiple follow-up assessments during infancy. However, we acknowledge that there are a number of potential limitations. Our sample size was small relative to the initial cohort and only $66 \%$ of this subset had available measures of body composition in early infancy, representing the possibility of bias and/or imprecision. Despite this, the current study cohort did not differ significantly from the remainder of the cohort regarding exposure and outcome measures or major sociodemographic characteristics. Other study limitations include that maternal prepregnancy BMI was not available, that infant feeding was not quantified and that direct body composition measurements were not available beyond 2 months.

In conclusion, we have shown, in a well-characterised birth cohort, that umbilical cord blood leptin is positively associated with direct measures of adiposity at birth and inversely associated with conditional weight gain in the first 2 months of life, which is largely driven inverse associations with changes in adiposity. Fetal and early postnatal life have been identified as particularly sensitive periods of development, during which disturbances can result in longterm metabolic consequences, 'programming' later disease risk (45). Lower neonatal leptin may represent one of the mechanisms underlying the association between an altered intrauterine environment, rapid postnatal weight gain and subsequent obesity risk. As we examined conditional change in weight and body composition, the magnitude of the effect of cord blood leptin on weight gain and changes in adiposity in early infancy is difficult to interpret. Nevertheless, we have shown that higher cord leptin concentrations play a role in moderating fat accretion in early infancy. Longitudinal data on body composition beyond infancy would allow for the examination of whether this association with adiposity persists and for the determination of any clinical significance. Further investigation into the determinants and long-term consequences of neonatal and early-life leptin concentrations is required.

\section{Declaration of interest}

The authors declare that there is no conflict of interest that could be perceived as prejudicing the impartiality of the research reported.

\section{Funding}

This research was funded by the National Children's Research Centre (NCRC).

\section{Author contribution statement}

M K and C ní C conceptualised and designed the study, completed the statistical analysis and drafted the manuscript. $\mathrm{M} \mathrm{K}$ was responsible for the final content. C ní C carried out the biochemical analysis and database construction. The Cork BASELINE Birth Cohort Study is a multidisciplinary collaboration led by D M M (Principal Investigator), M K, J O'B H, A D I and L C K. L C K is the Principal Investigator of SCOPE Ireland. All authors read and approved the manuscript before submission.

\section{Acknowledgements}

We thank the families for their continued support and the Cork BASELINE Birth Cohort Study research team.

\section{References}

1 Baird J, Fisher D, Lucas P, Kleijnen J, Roberts H \& Law C. Being big or growing fast: systematic review of size and growth in infancy and later obesity. BMJ 2005331 929. (doi:10.1136/bmj.38586.411273.E0)

2 Druet C, Stettler N, Sharp S, Simmons RK, Cooper C, Smith GD, Ekelund U, Levy-Marchal C, Jarvelin MR, Kuh D et al. Prediction of childhood obesity by infancy weight gain: an individual-level meta-analysis. Paediatric Perinatal Epidemiology 201226 19-26. (doi:10.1111/j.1365-3016.2011.01213.x)

3 Dunger DB, Salgin B \& Ong KK. Session 7: Early nutrition and later health early developmental pathways of obesity and diabetes risk. Proceedings of the Nutrition Society 200766 451-457. (doi:10.1017/ S0029665107005721)

4 Leunissen RW, Kerkhof GF, Stijnen T \& Hokken-Koelega A. Timing and tempo of first-year rapid growth in relation to cardiovascular and metabolic risk profile in early adulthood. JAMA $20093012234-2242$. (doi:10.1001/jama.2009.761)

5 Karaolis-Danckert N, Buyken AE, Kulig M, Kroke A, Forster J, Kamin W, Schuster A, Hornberg C, Keil T, Bergmann RL et al. How pre- and postnatal risk factors modify the effect of rapid weight gain in infancy and early childhood on subsequent fat mass development: results from the Multicenter Allergy Study 90. American Journal of Clinical Nutrition $2008 \mathbf{8 7} 1356-1364$.

6 Chrestani MA, Santos IS, Horta BL, Dumith SC \& de Oliveira Dode MA. Associated factors for accelerated growth in childhood: a systematic review. Maternal and Child Health Journal 201317 512-519. (doi:10.1007/s10995-012-1025-8)

7 Zhang Y, Proenca R, Maffei M, Barone M, Leopold L \& Friedman JM. Positional cloning of the mouse obese gene and its human homologue. Nature 1994372 425-432. (doi:10.1038/372425a0)

8 Christou H, Serdy S \& Mantzoros CS. Leptin in relation to growth and developmental processes in the fetus. Semininars in Reproductive Medicine 200220 123-130. (doi:10.1055/s-2002-32503)

9 Friedman JM \& Halaas JL. Leptin and the regulation of body weight in mammals. Nature 1998395 763-770. (doi:10.1038/27376)

10 Bouret SG, Draper SJ \& Simerly RB. Trophic action of leptin on hypothalamic neurons that regulate feeding. Science $2004 \mathbf{3 0 4}$ 108-110. (doi:10.1126/science.1095004)

11 Ong KK, Ahmed ML, Sherriff A, Woods KA, Watts A, Golding J \& Dunger DB. Cord blood leptin is associated with size at birth and predicts infancy weight gain in humans. ALSPAC Study Team. Avon Longitudinal Study of Pregnancy and Childhood. Jounal of Clinical Endocrinology and Metabolism 199984 1145-1148. (doi:10.1210/jcem.84.3.5657)

12 Parker M, Rifas-Shiman SL, Belfort MB, Taveras EM, Oken E, Mantzoros C \& Gillman MW. Gestational glucose tolerance and cord blood leptin levels predict slower weight gain in early infancy. Journal of Pediatrics 2011158 227-233. (doi:10.1016/j.jpeds.2010.07.052)

13 Alexe DM, Syridou G \& Petridou ET. Determinants of early life leptin levels and later life degenerative outcomes. Clinical Medicine and Research 20064 326-335. (doi:10.3121/cmr.4.4.326)

14 Attig L, Solomon G, Ferezou J, Abdennebi-Najar L, Taouis M, Gertler A $\&$ Djiane J. Early postnatal leptin blockage leads to a long-term leptin resistance and susceptibility to diet-induced obesity in rats. International Journal of Obesity 200832 1153-1160. (doi:10.1038/ijo.2008.39) 
15 Vickers MH \& Sloboda DM. Leptin as mediator of the effects of developmental programming. Best Practice \& Research Clinical Endocrinology \& Metabolism 201226 677-687. (doi:10.1016/j. beem.2012.03.005)

16 Bouret SG \& Simerly RB. Developmental programming of hypothalamic feeding circuits. Clinical Genetics 200670 295-301. (doi:10.1111/j.1399-0004.2006.00684.x)

17 Sarr O, Yang K \& Regnault TR. In utero programming of later adiposity: the role of fetal growth restriction. Journal of Pregnancy 20122012 134758. (doi:10.1155/2012/134758)

18 Desai M, Gayle D, Han G \& Ross MG. Programmed hyperphagia due to reduced anorexigenic mechanisms in intrauterine growthrestricted offspring. Reproductive Sciences 200714 329-337. (doi:10.1177/1933719107303983)

19 Tung WK, Lin SJ, Hwang YS, Wu CM, Wang YH \& Tsai WH. Association of cord plasma leptin with birth size in term newborns. Pediatrics and Neonatology 200950 255-260. (doi:10.1016/S18759572(09)60073-5)

20 Mantzoros CS, Rifas-Shiman SL, Williams CJ, Fargnoli JL, Kelesidis T \& Gillman MW. Cord blood leptin and adiponectin as predictors of adiposity in children at 3 years of age: a prospective cohort study. Pediatrics 2009123 682-689. (doi:10.1542/peds.2008-0343)

21 Brunner S, Schmid D, Huttinger K, Much D, Bruderl M, Sedlmeier EM, Kratzsch J, Amann-Gassnerl U, Bader BL \& Hauner H. Effect of reducing the $n-6 / n-3$ fatty acid ratio on the maternal and fetal leptin axis in relation to infant body composition. Obesity 201422 217-224. (doi:10.1002/oby.20481)

22 O'Donovan SM, Murray DM, Hourihane JO, Kenny LC, Irvine AD \& Kiely M. Cohort profile: The Cork BASELINE Birth Cohort Study: babies after SCOPE: evaluating the longitudinal impact on neurological and nutritional endpoints. International Journal of Epidemiology 201544 764-775. (doi:10.1093/ije/dyu157)

23 Kenny LC, Black MA, Poston L, Taylor R, Myers JE, Baker PN, McCowan LM, Simpson NA, Dekker GA, Roberts CT et al. Early pregnancy prediction of preeclampsia in nulliparous women, combining clinical risk and biomarkers: the Screening for Pregnancy Endpoints (SCOPE) international cohort study. Hypertension 201464 644-652. (doi:10.1161/HYPERTENSIONAHA.114.03578)

24 Pan H \& Cole TJ. LMSgrowth, a Microsoft Excel add-in to access growth references based on the LMS method. Version 2.2. 2012, 2007 (available at: http://www.healthforallchildren.co.uk/).

25 SACN/RCPCH Expert Group. Application of the WHO Growth Standards in the UK. London, UK: Stationery Office, 2007.

26 SACN/RCPCH Expert Group. Consideration of issues around the use of BMI centile thresholds for defining underweight, overweight and obesity in children aged 2-18 years in the UK, 2012.

27 McCowan LM, Roberts CT, Dekker GA, Taylor RS, Chan EH, Kenny LC, Baker PN, Moss-Morris R, Chappell LC \& North RA. Risk factors for small-for-gestational-age infants by customised birthweight centiles: data from an international prospective cohort study. BJOG 2010117 1599-1607. (doi:10.1111/j.1471-0528.2010.02737.x)

28 Griffiths LJ, Smeeth L, Hawkins SS, Cole TJ \& Dezateux C. Effects of infant feeding practice on weight gain from birth to 3 years. Archives of Diseases in Childhood 200994 577-582. (doi:10.1136/adc.2008.137554)

29 Meier U \& Gressner AM. Endocrine regulation of energy metabolism: review of pathobiochemical and clinical chemical aspects of leptin, ghrelin, adiponectin, and resistin. Clinical Chemistry 200450 1511-1525. (doi:10.1373/clinchem.2004.032482)

30 Harris RB. Direct and indirect effects of leptin on adipocyte metabolism. Biochimica et Biophysica Acta 20141842 414-423. (doi:10.1016/j.bbadis.2013.05.009)
31 Attig L, Djiane J, Gertler A, Rampin O, Larcher T, Boukthir S, Anton PM, Madec JY, Gourdou I \& Abdennebi-Najar L. Study of hypothalamic leptin receptor expression in low-birth-weight piglets and effects of leptin supplementation on neonatal growth and development. American Journal of Physiology-Endocrinology and Metabolism 2008295 E1117-E1125. (doi:10.1152/ajpendo.90542.2008)

32 Czaja K, Barb CR \& Kraeling RR. Hypothalamic neurons innervating fat tissue in the pig express leptin receptor immunoreactivity. Neuroscience Letters 2007425 6-11. (doi:10.1016/j.neulet.2007.08.002)

33 Ozdemir U, Gulturk S, Aker A, Guvenal T, Imir G \& Erselcan T. Correlation between birth weight, leptin, zinc and copper levels in maternal and cord blood. Journal of Physiology and Biochemistry 2007 63 121-128. (doi:10.1007/BF03168223)

34 Walsh JM, Byrne J, Mahony RM, Foley ME \& McAuliffe FM. Leptin, fetal growth and insulin resistance in non-diabetic pregnancies. Early Human Development 201490 271-274. (doi:10.1016/j. earlhumdev.2014.03.007)

35 Misra VK, Straughen JK \& Trudeau S. Maternal serum leptin during pregnancy and infant birth weight: the influence of maternal overweight and obesity. Obesity 201321 1064-1069. (doi:10.1002/oby.20128)

36 Karakosta P, Georgiou V, Fthenou E, Papadopoulou E, Roumeliotaki T, Margioris A, Castanas E, Kampa M, Kogevinas M \& Chatzi L. Maternal weight status, cord blood leptin and fetal growth: a prospective mother-child cohort study (Rhea study). Paediatric and Perinatal Epidemiology 201327 461-471. (doi:10.1111/ppe.12074)

37 Catalano PM, Presley L, Minium J \& Hauguel-de Mouzon S. Fetuses of obese mothers develop insulin resistance in utero. Diabetes Care 2009 32 1076-1080. (doi:10.2337/dc08-2077)

38 Luo ZC, Nuyt AM, Delvin E, Fraser WD, Julien P, Audibert F, Girard I, Shatenstein B, Deal C, Grenier E et al. Maternal and fetal leptin, adiponectin levels and associations with fetal insulin sensitivity. Obesity 201321 210-216. (doi:10.1002/oby.20250)

39 Ferretti G, Cester AM, Bacchetti T, Raffaelli F, Vignini A, Orici F, Martino C \& Tranquilli A. Leptin and paraoxonase activity in cord blood from obese mothers. Journal of Maternal-Fetal and Neonatal Medicine 201427 1353-1356. (doi:10.3109/14767058.2013.858319)

40 Karakosta P, Chatzi L, Plana E, Margioris A, Castanas E \& Kogevinas M. Leptin levels in cord blood and anthropometric measures at birth: a systematic review and meta-analysis. Paediatric and Perinatal Epidemiology 201125 150-163. (doi:10.1111/j.13653016.2010.01163.x)

41 McMillen IC, Edwards LJ, Duffield J \& Muhlhausler BS. Regulation of leptin synthesis and secretion before birth: implications for the early programming of adult obesity. Reproduction 2006131 415-427. (doi:10.1530/rep.1.00303)

42 Salbe AD, Weyer C, Lindsay RS, Ravussin E \& Tataranni PA. Assessing risk factors for obesity between childhood and adolescence: I. Birth weight, childhood adiposity, parental obesity, insulin, and leptin. Pediatrics 2002110 299-306. (doi:10.1542/peds.110.2.299)

43 Fleisch AF, Agarwal N, Roberts MD, Han JC, Theim KR, Vexler A, Troendle J, Yanovski SZ \& Yanovski JA. Influence of serum leptin on weight and body fat growth in children at high risk for adult obesity. Journal of Clinical Endocrinology and Metabolism 200792 948-954. (doi:10.1210/jc.2006-1390)

44 Boeke CE, Mantzoros CS, Hughes MD, L Rifas-Shiman S, Villamor E, Zera CA \& Gillman MW. Differential associations of leptin with adiposity across early childhood. Obesity 201321 1430-1437. (doi:10.1002/oby.20314)

45 Gillman MW. The first months of life: a critical period for development of obesity. American Journal of Clinical Nutrition 2008 87 1587-1589.

Received 20 May 2016

Revised version received 29 July 2016

Accepted 15 August 2016 